\title{
Refórma da Organização Judiciária do Estado de São Paulo
}

\author{
( P A R E C E R ) (*) \\ Gabriel de Rezende Filho \\ S. Soares de Faria \\ Francisco Morato
}

Não é preciso encarecer a importância da organização judiciária, pois impossível é a vida dos homens em sociedade sem que os seus direitos e interesses sejam eficazmente amparados pelo Poder Judiciário.

Aliar à simplicidade e segurança na repartição das atribuições jurisdicionais entre os órgãos diretos da Justiça a aplicação de certos princípios capazes de impedir a morosidade no trato e decisão das lides - eis o ideal em matéria de organização judiciária.

Obra complexa, todavia, condicionada como se acha, pelas condições e forças do exário público, que ha de fazer face às enormes despesas que a mantença de um bom aparelho judiciário acarreta.

Examinando-se a organização do Estado de São Paulo, verifica-se que, desde o albor da República, grande foi a preocupação dos nossos estadistas - como se infere dos. vários projetos e das leis sucessivas - em dotar o nosso Estado de um eficiente aparelhamento judiciário, obedecendo aos ensinamentos dos mestres a propósito do assunto.

( ) Parecer da comissão designada pelo diretor da Faculdade de Direito e aprovado pela Congregação, em sessão de 10 de setembro de 1941. 
Vale a pena recordar, ligeiramente, os aspectos principais da evolução da nossa organização judiciária, especialmente quanto à investidura e distribuição dos órgãos diretos do Poder Judiciário.

Proclamada a República, São Paulo cuidou imediatamente de modificar, como, aliás, o exigia, o sistema introduzido pela Constituição de 24 de fevereiro de 1891, instituindo, par a par, a justiça federal e a justiça local, a velha organização judiciária que nos legara o Império.

Suprimindo os termos e os juizes municipais, a lei $n .{ }^{\circ}$ 80, de 25 de agosto de 1892, dividiu o Estado em comarcas e distritos de paz.

Nas comarcas funcionavam os juizes de direito e, nos distritos, os juizes de paz.

Determinou a citada lei a competência destas autoridades judiciárias, regulando os casos e a fórma de substituição dos juizes de direito pelos juizes de paz.

o Tribunal de Justiça, de segunda instância, tinha a sua séde na Capital e estenderia a sua jurisdição sobre todo o território do Estado.

Mantinha-se, assim, a tradição: juizes singulares na primeira, e juizes colegiais, na segunda instância.

Com o tempo, porém, foi sentida a necessidade de ser aperfeiçoado o aparelho judiciario, principalmente quanto à substituição dos juizes de direito e à diminuição do serviço do Tribunal de Justiça.

A experiência indicava que era conveniente afastar os juizes de paz da função de substitutos dos juizes de direito, porque tais juizes, em geral leigos e eletivos, meros instrumentos dos partidos políticos, constituiam quasi uma calamidade, uma vez elevados às funções de juizes togados.

Dentre as tentativas que, por essa época, se fizeram para a refórma da nossa Justiça, cumpre destacar o projeto do dr. Sousa Lima, sobre o qual se pronunciou, em 1897, a Congregação desta Faculdade, por intermédio de uma Comissão composta dos saudosos e eminentes Profes- 
sores João Mendes Junior, Basílio Rodrigues dos Santos e Rafiel Corrêa da Silva.

Este projeto, visando melhorar o aparelhamento judiciário do Estado, quanto à substituição dos juizes de direito e à diminuição do serviço do Tribunal de Justiça, aventava a criação dos juizes substitutos e a de circúitos de comarcas, com tribunais de circúitio.

Os juizes substitutos teriam por função substituir os juizes de direito, em suas ausências e impedimentos.

Com tal inovação, os juizes de paz, embora continuando a exercer funções jurisdicionais em seus distritos e dentro de sua alçada, não seriam mais convocados para substituir os juizes togados.

Os circúitos de comarcas compreenderiam várias comarcas, tendo por séde uma delas.

E nos doze circúitos, em que o Estado se dividiria, instalar-se-iam tribunais civis e criminais, compostos de juizes de direito de cada circúito, em número não inferior a sete e nem superior a doze.

Cada tribunal, tendo, como Presidente, o juiz de direito da séde do circúito, reunir-se-ia, durante cinco dias, nos meses de fevereiro, máio, agosto e novembro.

Os juizes de direito, que houvessem funcionado na causa em primeira instância, não teriam voto por ocasião do julgamento dos respectivos recursos.

Quanto à competência, os Tribunais de circúito julgariam as apelações das sentenças dos juizes de direito do respectivo circúito, em feitos de valor não excedente a 5:000\$000.

Sem embargo das excelentes medidas deste projeto, não as aceitou a aludida Comissão de Professores da Faculdade, justificando-se com argumentos bastante interessantes.

Em relação aos substitutos, a Comissão talvez haja discordado de sua criação, pelo excessivo formalismo do projeto quanto à convocaçã̃o e efetivo exercício de tais auto- 
ridades, o que, parece, ocasionaria a procrastinação das demandas.

Mas, o que de todo não agradou à Comissão foi a idéia dos tribunais de circúito.

Entre outros inconvenientes, apontava a Comissão a fatal diminuição da confiança nas decisões e da autoridade da jurisprudência, mercê da inevitavel variedade de acórdãos proferidos por doze tribunais regionais, e, ainda, a possibilidade de mais demorada se tornar a solução dos recursos, dado o exíguo prazo marcado pelo projeto para as sessões dos referidos tribunais.

O parecer, neste ponto, era incisivo: "Não ha publicista algum que, tratando de determinar as condições de uma boa organização judiciária, deixe de assinalar, como resultado de todas as meditações e experiências, o seguinte: convém multiplicar os distritos de jurisdição de primeira instância, afim de que haja juiz próximo do domicílio das partes; convém reduzir, tanto quanto possível, o número dos distritos de jurisdição de segunda instância, 'afim de que os juizes superiores estejam arredados do domicílio das partes. A imparcialidade dos juizes superiores será mais segura, si estiverem afastados do teatro em que os negócios tiveram origem, porque estarão sobranceiros às perigosas sugestões de localidade. Aplicando tais considerações aos circúitos de comarcas, facil é compreender quão pouco segura estará a isenção dos juizes de direito que compõem o respectivo Tribunal; as mesmas influências locais, que preponderam nas comarcas e quasi sempre são a causa de injustiças na primeira instância, facilmente estenderão ao circúito a sua ação deletéria; por outro lado, não é conforme à índole humana reformar a sentença de um colega, que, conquanto não vote, está presente ao Tribunal, coagindo os outros na discussão, impedindo, em suma, a liberdade na verificação e declaração dos erros do processo e da mesma sentença; além disso, sob o pretexto de recíproca fôrça moral, não raras vezes será sacrificado o direito dos recorrentes; e, quando assim não seja, essa reu- 
nião de juizes de igual categoria, fiscalizando-se reciprocamente, dará em resultado muitos votos dados mais por espírito de emulação do que por espírito de justiça. Acrescente-se a tudo isso a vacilação que fatalmente surgirá das decisões desses doze Tribunais, quer no modo de considerar as relações de direito, quer no modo de discernir as regras que as dominam, quer na apreciação e solução das incertezas que obscurecem os elementos da decisão, produzindo uma diversidade de estilos e arestos em prejuizo da uniformidade da jurisprudência; esse resultado pernicioso será consequência, não só da natural falibilidade, não só das referidas contingências locais, como tambem, segundo a expressão de BAcon, propter emulationem curiarum".

Em 1911, o Presidente do Estado, Conselheiro Rodrigues Alves, encarregou o sábio mestre JoÃo Mendes JunIor de reorganizar a nossa justiça.

Apresentou o eminente jurista um trabalho notavel pela sua simplicidade e perfeita compreensão das nossas necessidades.

Conservava o projeto de JoÃo Mendes o tradicional sistema da divisão territorial do Estado em comarcas e distritos de paz, mantendo o Tribunal de Justiça, como único Tribunal de segunda instância, dividido em duas Câmaras, a Civil e a Criminal.

A sua principal inovação era a da exigência do exame de suficiência dos candidatos à magistratura.

Observe-se, de passagem, que a Constituição paulista de 14 de julho de 1891 estabelecia, para a primeira investidura no cargo de juiz de direito, o concurso de provas, mas esta disposição fora revogada pela refórma constitucional de 9 de julho de 1895 .

O exame de suficiência, planejado por João Mendes, seria prestado todos os anos perante o Tribunal de Justiça, em duas épocas, compondo-se a respectiva Comissão do Presidente do Tribunal, de dois desembargadores e de dois advogados. 
Os candidatos seriam classificados em habilitados e inhabilitados, cumprindo ao Govêrno fazer as nomeações de acôrdo com a lista dos habilitados que lhe seria enviada, após os julgamentos, pelo Tribunal.

Não haveria graduação propriamente entre as comarcas, classificadas em três entrâncias; apenas, para o efeito da investidura, os juizes começariam a carreira em comarcas de primeira entrância.

Apezar de estabelecer o projeto a substituição recíproca dos juizes de direito, em. suas ausências e impedimentos, continuaria a praticar-se o sistema de se entregarem aos juizes de paz os atos informatórios e ordinatórios do juizo, quando assumissem as funções de juiz togado.

Fiel às suas idéias, manifestadas no parecer de 1897, a que ha pouco aludimos, Joĩ̃o Mendes manifestou-se contrário, no seu projeto de 1911, à criação dos cargos de juizes substitutos e de tribunais regionais de segunda instância.

O trabalho do mestre sofreu várias críticas e não pequena oposição no Congresso do Estado, acabando, afinal, por ficar esquecido numa das pastas da Comissão de Justiça da Câmara dos Deputados.

Só em 1921 foi possivel a reorganização judiciária do Estado.

Neste ano, promulgou o Presidente. Washington Luís a lei . $^{\circ} 1.795$, de 17 de novembro, cujos pontos culminantes eram a exigência do concurso de provas e títulos para o ingresso na magistratura e a criação da classe dos juizes substitutos.

Ao par destas inovações, devemos salientar tambem a delimitação dos casos de substituição dos juizes de direito pelos juizes de paz, pois os substitutos passaram a exercer, quandol convocados, as funções jurisdicionais com plenitude em vários casos, e com restrições em outros, segundo o sistema da referida lei.

Classificadas as comarcas em entrâncias, exigiram-se algumas condições, entre elas o estágio, para o acesso na carreira. 
Demos com esta lei, sem dúvida alguma, um passo adiante na melhoria do nosso aparelho judiciário, e quando tudo indicava que os nossos legisladores só haveriam de retocá-la em pontos secundários, si mistér se fizesse, surgiu a lei.$^{\circ}$ 2.186, de 30 de dezembro de 1926, que nos fez retrogradar, de certa maneira, para os tempos imperiais.

Com efeito, preocupado o legislador com a necessidade de aliviar o intenso trabalho do Tribunal de Justiça, resolveu criar a classe dos juizes preparadores, outorgando tambem, em certos casos, competência aos juizes de direito para decidirem recursos, em última instância.

Os juizes preparadores, com exercício na Capital e nas comarcas de terceira entrância, preparavam os feitos de valor inestimavel ou de valor superior a 5:000\$000, reservando-se o seu julgamento aos juizes de direito; e tinham competência para conhecer e julgar os feitos de valor até 5:000\$000.

Os juizes de direito, por sua vez, julgavam os recursos das sentenças proferidas, dentro de sua alçada, pelos preparadores.

Nas comarcas de primeira e segunda entrâncias, onde não havia preparadores, cabia aos juizes de direito julgar os recursos das sentenças proferidas por juizes de direito das comarcas vizinhas em feitos de valor não excedente a $5: 000 \$ 000$.

Este sistema não produziu, porém, bons resultados, porque caótica se tornou a jurisprudência, mercê da variedade de decisões proferidas por juizes de direito em matéria de recursos, ferindo, ademais, em cheio, o clássico princípio de que os recursos devem ser julgados por juizes colegiais.

Tais foram os reclamos da opinião pública, que o Congresso do Estado reorganizou, mais uma vez, a nossa justiça, por meio da lei n..$^{\circ} .222$, de 13 de dezembro de 1927, suprimindo os juizes preparadores e concentrando no Tribunal de Justiça o serviço de segunda instância. 
Algumas leis posteriores têm modificado o aparelho judiciário do Estado, principalmente após o movimento revolucionário de 1930 , seja aumentando o número de juizes de primeira e de segunda instância, seja suprimindo a função jurisdicional dos juizes de paz, seja alterando, em pontos secundários, a citada lei . $^{\circ} 2.222$.

Tais alterações, todavia, não carecem ser mencionadas, pois não implicaram em modificação substancial do nosso sistema judiciário.

O novo Código de Processo Civil determinou a necessidade de se adaptar a nossa organização judiciária às suas exigências.

Com ef eito, inspirando-se em princípios publicísticos e adotando, embora de maneira atenuada, o sistema da oralidade, exige o Código a presença do juiz nas audiências de instrução e julgamento - fase máxima das causas - impondo-lhes, além disso, o dever de despachar e setenciar em prazos curtos e peremptórios.

$O$ decreto lei $n^{\circ} 11.058$, de 26 de abril de 1940, que reorganizou a nossa justiça, procurou atender a estes imperativos, tanto quanto possível, dentro das forças do erário público.

Criaram-se, na Capital, três Varas de Juizes dos Feitos da Fazenda Federal, Estadoal e Municipal e a classe dos juizes-adjuntos.

O Tribunal de Apelação foi dividido em duas Secções, a Civil e a Criminal. A Civil, sub-dividida em dois Grupos de Câmaras, cada um deles com duas Câmaras; e a Criminal sub-dividida, por sua vez, em duas Câmaras.

A experiência de um ano ja demonstrou que ha conve-

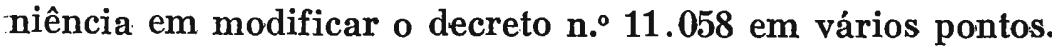

A comissão of erece as seguintes sugestões para a reorganização da nossa Justiça, que foram apresentadas ao Govêrno do Estado por um de seus membros, o Professor dr. Francisco Morato. 
"Achamos defeituosa e mal inspirada a citada lei em vários de seus tópicos, como adiante salientaremos, tomando apenas alguns dos mais importantes e dos que mais inconvenientes se têm revelado na prática forense.

Acima de tudo e em primeira plana lembramos uma idéia geral, que implicaria a abrogação de todas as leis paulistas de organização dos serviços de justiça, idéia pela qual temos propugnado de ha muito e que reputamos à altura do movimento judiciário e da grandeza sempre prosperada e irreprimivel do nosso Estado: a criação de Tribunais Regionais.

E a idéia que em princípio e larga visão pregaram Sousa lima e o grande Rafael Corrêa da Silva, quando aconselhavam o Estado a enfrentar o problema de um modo definitivo, com a coragem e conciência de sua responsabilidade no seio da Federação; única de molde a evadir as contínuas refórmas retalhadas e de emergência, única que traz em seu bojo a estrutura, a plasticidade indispensavel para acomodar-se às mutações no círculo do tempo e do espaço, como simples retoque de fórma, sem sacrifício do seu fundo orgânico.

Em suas linhas mestras, esboçar-se-ia o plano em debuxo singelo: os juizes de direito, preparando e julgando feitos até determinada alçada; os Tribunais Regionais preparando e julgando as causas acima dessa alçada, bem como decidindo os recursos das sentenças e despachos dos juizes de direito; o Tribunal de Justiça, desempenhando certas funções privativas, conhecendo dos recursos dos Tribunais Regionauis e revendo, em restritas hipóteses, os arestos dos Tribunais Regionais, em recurso das decisões dos juizes de direito.

Seria o projeto Sousa Lima, semelhante no pensamento fundamental, mas diverso na instituição, composição e funcionamento dos órgãos judicantes, a saber:

Conservar-se-iam os juizes de dineito de comarca, assim como os das Varas de Família e dos Feitos da Fazenda Federal, Estadoal e Municipal da Capital (os daquelas e os 
destas com competência cumulativa dentro das esferas de sua jurisdição) todos competentes para o processo e julgamento das causas dentro de determinada alçada; com recurso para o respectivo Tribunal Regional, salvo das sentenças dos juizes de direito da Capital, nas causas em que fôr interessada a União, como autora, ré, assistente ou opoente, em que não haverá alçada e o recurso será direto para o Supremo Tribunal Federal (CONSTITUIÇAO, art. 109).

Criar-se-iam os Tribunais Regionais de três juizes, pelo grupamento de tantas comarcas quantas reclamarem os respectivos movimentos forenses, investidos de competência para julgar os recursos de primeira instância, processar e julgar as causas excedentes da alçada dos juizes de direito, com recurso para o Tribunal de Justiça. Aos três juizes caberia cumulativamente, mediante distribuição, o expediente e preparo do feito de sua alçada.

o Tribunal de Justiça ficaria na cúpula, com competência privativa para o processo e julgamento das questões que lhe cabem pelas leis vigentes, para os assuntos administrativos de sua alçada, para o julgamento dos rcursos dos Tribunais Regionais e para decisão, em instância de revisão, dos arestos definitivos dos mesmos Tribunais em recurso das sentenças dos juizes de direito, quando o julgado fôr de manifesta injustiça ou implicar contradição na jurisprudência.

o Tribunal de Justiça dividir-se-ia em Câmara Civil e Câmara Criminal. Funcionaria em sessão plena ou sessão de Câmara. O julgamiento de Câmara seria por turmas, como se pratica atualmente, ou por turnos, com a presença de todos os desembargadores, facultado a estes intervir nos debates; coisa perfeitamente possivel com a redução dos serviços e que prestigiará enormemente, assim as decisões proferidas como o próprio Tribunal.

Dada a relação íntima entre a lei de processo e a de organização judiciária, ambas partes integrantes da processualística ou direito judiciário, talvez conviesse sobreestar 
o projeto com este sistema visceralmente novo, à espera do novo Código de Processo Criminal, que deve aparecer breve para execução do Código Penal a vigorar de $10^{\circ}$ de janeiro em diante.

A reforma não acarretará aumento demasiado de despesas, pois, com o aproveitamento de alguns desembargadores para presidentes dos Tribunais com séde na Capital e dos juizes adjuntos promovidos para as varas que se vagarem pelos chamamentos dos seus titulares para o Tribunal de circúito, o acréscimo de órgãos judicantes será nulo ou de pequena monta.

São Paulo, no esplendor de sua opulência e cultura, no zelo e carinho com que lhe cumpre manear o serviço da justiça, sem demasiada avareza neste relevante capítulo da administração pública, pode e deve afrontar a grande reforma, resoluta e corajosamente.

Suposto que não convém acolher a idéia por motivos de oportunidade ou economia, lembraremos algumas medidas parciais, dentro do sistema vigente e particularmente em face da lei 11.058 de 1940 .

E' a primeira a supressão dos juizes adjuntos e, compensatoriamente, a criação de mais oito varas cíveis na Capital.

A criação de adjuntos, recrutados entre magistrados de primeira e segunda entrâncias, promovidos à Capital, sem estágio nem observância da escala hierárquica, com atribuições judicantes quasi tão vastas e importantes como as dos juizes efetivos, foi um invento desastroso, que, sobre quebrantar o critério paritário do preparo e assunto profissional, havia de dar, como deu, os peiores resultados. Não ha porventura uma só voz que o não condene, entre os que exercitam nas lutas do magistério e dos auditórios da justiça, embora entre os adjuntos haja varios de alta competência e valor. 
O problema político da eśtabilidade destes funcionários se contornaria sem embaraço algum, com a promoção de uma parte deles para as comarcas de terceira entrância que se vagariam e de outra parte como preparadores dos juizes criminais aqui da Capital.

Está subentendido que se extinguiriam igualmente os adjuntos das comarcas, onde, ao luxo de mais de uma vara, se acrescenta a liberalidade destes órgãos auxiliantes.

Onde as varas existentes forem insuficientes para os trabalhos, criem-se novas.

Lembrariamos outrossim que, criando-se, além das oito varas cíveis novas, duas das famílias e sucessões, como pensa o Conselho da Ordem dos Advogados, seria de rigor criarse igualmente mais um cartório desta especialidade.

Lembrariamos ainda que se prescrevesse para os juizes de direito prazo de expediente mais dilatado do que observam na Capital.

Lembrariamos por último se retificasse ligeiramente a classificação das comarcas, de tal arte a corrigir a flagrante desigualdade de manter-se como de segunda entrância comarcas que evidentemente deveriam estar na terceira, quais sejam Piracicaba, Araraquara, Sorocaba, São Carlos e Jundiaí.

Esta desigualdade ou injustiça melhor se saliente si o seguinte se considera e particulariza: Piracicaba com uma vara tem movimento forense igual ao de Ribeirão Preto com duas varas e um adjunto; entretanto esta é de terceira entrância e aquela de segunda.

Si o Govêrno quizer ouvir a este propósito o parecer do Presidente do Tribunal de Apelação e do Corregedor Geral, que são os que por oficio têem mais conhecimento da matéria, para logo ha-de verificar a procedência de nossas arguições". 